\title{
Severity of Symptoms of Systemic Inflammatory Response Syndrome and Congestive Heart Failure Caused by Chronic Aortic Stenosis and Its Pharmacological Correction
}

\author{
G. V. Sukoyan1*, D. Iu. Ionov², P. A. Galenko-Iaroshevsky², A. V. Zelenskaya², V. V. Golovach1 \\ ${ }^{1}$ International Centre of Introduction of New Biomedical Technology, Tbilisi, Georgia \\ ${ }^{2}$ Department of Pharmacology, Kuban State of Medical University, Krasnodar, Russia \\ Email: *galinasukoian@gmail.com
}

How to cite this paper: Sukoyan, G.V., Ionov, D.Iu., Galenko-Iaroshevsky, P.A., Zelenskaya, A.V. and Golovach, V.V. (2017) Severity of Symptoms of Systemic Inflammatory Response Syndrome and Congestive Heart Failure Caused by Chronic Aortic Stenosis and Its Pharmacological Correction. World Journal of Cardiovascular Diseases, 7, 465-476.

https://doi.org/10.4236/wjcd.2017.712046

Received: October 10, 2017

Accepted: December 17, 2017

Published: December 20, 2017

Copyright ( $) 2017$ by authors and Scientific Research Publishing Inc. This work is licensed under the Creative Commons Attribution International License (CC BY 4.0).

http://creativecommons.org/licenses/by/4.0/

\section{(c) (i) Open Access}

\begin{abstract}
Systemic inflammatory response syndrome (SIRS) is one of the key accompanied states that worsens severity of congestive heart failure (CHF) and leads refractory CHF to conventional therapy. We investigated whether the cessation of the symptoms and signs of SIRS prevents the progression of the CHF caused by chronic aortic stenosis in rabbits. 8 weeks after induced CHF by left descending coronary artery stenosis, all animals were randomly assigned into 3 groups: control (CG) - without therapy (infusion of $0.9 \% \mathrm{NaCl}$ ); main Ireceive $\mathrm{mg} / \mathrm{kg}$ of Adenocin ${ }^{\circledR}$ dissolved in water for injection i.v., once daily and main II-animals receive $0.25 \mathrm{mg} / \mathrm{kg}$ enalapril i.m, furosemide $1.0 \mathrm{mg} / \mathrm{kg}$ i.v. (bolus) and pimobendan $0.1 \mathrm{mg} / \mathrm{kg}$ i.v. once daily. All animals were euthanized after 14 days of the beginning of treatment. Long-term aortic stenosis leads to a simultaneously developing of CHF, diagnosed by developing cardiac hypertrophy, increased level of BNP and myocardial oedema and SIRS, confirmed by increasing markers and symptoms of endotoxemia, tissue dysoxia and decreasing reserve ability of intrinsic defense systems. Restoration of myocardium redox-potential and level of NAD under treatment with Adeno$\operatorname{cin}^{\circledR}$ leads unlike combined treatment with enalapril, furosemide and pimobendan to restoration, the regulatory pathways of TNF- $\alpha$ synthesis, cessation of the hypoxic/ischemic, lysosomal dysfunction and free radical-induced damage in myocardium and symptoms of CHF. Potential important link between cellular metabolism (hypoxia/ischemia), endotoxemia and disturbances in intrinsic defense system is the level of redox-potentail, NAD/NADH in myocardium.
\end{abstract}


Influence of oxidized form of NAD-containing positive inotropic drug Adenocin ${ }^{\circledR}$ leads to the decreasing symptoms of CHF and beneficial action occurs on all the key links of SIRS.

\section{Keywords}

Systemic Inflammatory Response Syndrome, Heart Failure, NAD-Containing Positive Inotropic Drug

\section{Introduction}

Systemic inflammatory response syndrome (SIRS) where the inciting stimulus is "sterile", is common in clinical practice, which is observed in the most diverse etiology and pathogenesis of non-identical states. SIRS is an essential and determining element of shock of different ethiology, sepsis, burns and traumatic disease, including closed craniocerebral trauma and operating; uremia; diseases of the broncho-pulmonary system; oncological processes and surgical diseases that accompany pancreatic necrosis and acute pancreatitis, peritonitis [1]-[11]. The pathophysiology of cardiac arrest is also complex and induces a profound "sterile" SIRS, an activation of a wide range of interrelated pathways including endotoxemia mediators or endotoxin release; white blood cell and endothelial cell activation and expression of leukocyte adhesion molecules; profound tissue dysoxia, hyperproduction of oxygen radicals, disintegrated lysosomes; dysregulation of complement, coagulation, fibrinolytic and kallikrein systems. A detailed study of the clinical and laboratory changes revealed that the presence of the SIRS is not a threat, but it significantly reduces the quality of life of patients with uncomplicated myocardial infarction [6] [10] and chronic coronary heart disease [3] [4] [6], atherosclerosis, hypertension, heart disease, complicated by congestive heart failure regardless of etiology [3] [4] [7] [11]. Unlike sepsis, however, the "sterile" SIRS following cardiac arrest results from whole-body ischemia (i.e., low or no flow) and reperfusion (i.e., restoration of flow following ischemia). The development of a SIRS is passed into three stages. The first stage occurs in response to an insult, resulting in a local cytokine response primarily intended to evoke an inflammatory response to promote local cellular repair by recruiting cells from the reticuloendothelial and immune systems [1] [2] [5]. The second stage involves release of small quantities of cytokines into the systemic circulation in order to enhance, or magnify, this local response. This acute-phase response is usually tightly controlled by endogenous proinflammatory antagonists, and cytokines and immunologic mediators are kept in check by specific downregulation and antagonism. At the beginning of SIRS, toxins and metabolites enter the blood, lymph, interstitial fluid and spread of pathological focus (inflammation). If the protective system of the body is able to neutralize these substances, clinical symptoms may not occur; although any pathological conditions are associated with the accumulation in tissues and body fluids of normal or perverted 
metabolism products or ketone response, there is a latent or transient SIRS. At third stage, when decompensation protective and regulatory systems-excretion, detoxification (microsomal oxidation, conjugation), mononuclear-macrophage, begin the accumulation of endogenous toxins in the body. At this stage, the accumulation of toxic products occurs in organs and tissues locally, in the primary pathological focus with hyperergic inflammatory response and the rapid removal of the major mediators of inflammation. However, this can also lead to the simultaneous removal of the protective molecules, such as raising a protective cytokines TNF- $\alpha$ (tumor necrosis factor alpha). Thus, the known agents used in the treatment of SIRS, complicating for various diseases does not provide effective methods of influence on their own protective, detoxifying the body system.

The efficacy of specific therapies directed against these pathways (e.g., monoclonal antibodies, receptor or enzyme blockade) in clinical or experimental models of ischemia-reperfusion damage has been modest, at least in part, because of the diverse and interwoven nature of the pathways involved. More general therapies, such as steroids, have well-known negative effects. Increased oxidative stress and release of free radicals, including super oxide anion $\left(\mathrm{O}_{2}^{-}\right)$ and other reactive oxygen intermediates as well as endogenous antioxidant defense systems functioning disturbed and play a significant roles in the progression of both CHF and SIRS syndromes. Our earlier studies have demonstrated that Adenocin ${ }^{\circledR}$ show protective effects on severity of SIRS in CHF, caused by toxi-allergic myocarditis in experiments [7] [11] and in patients after bypass graft surgery [4] and congestive heart failure [5]. Moreover, in recent years, was observed that only Adenocin ${ }^{\circledR}$ in contrast to levosimendan, dobutamine and milrinone increased function capacity index and improve diastolic function of the myocardium in the conditions of maximum pressure overload [12] [13]. Adeno$\operatorname{cin}^{\circledR}$ is a combined cardiotonic drug with cardioprotective properties, and in contrast to other cardiotonic preparations, has a beneficial harmonized modulatory effect on cardiac hypertrophy progression throughout the improvement of functioning of intracellular system of energy supply, Ca-transport and myocardial myofibrils not only at rest, but at the overload conditions as well. The non-toxic, replacement therapy nature of Adenocin ${ }^{\circledR}$ as well as its multiple beneficial effects has made it one of the most attractive compounds to explore for its protective role under SIRS and ischemic genesis of CHF. The goal of our investigation was to determine the efficacy of Adenocin ${ }^{\circledR}$ in comparison with the traditional therapy to inhibit the development and progression the myocardial inflammation and endotoxemia, myocardium ischemic damage and restore the function of intrinsic defense system of the body as an important part of SIRS under congestive heart failure (CHF) caused by ischemic heart diseases.

\section{Materials and Methods}

\subsection{Animals}

All experiments were carried out on the chinchilla rabbits weighing between 2.5 
- $3.0 \mathrm{~kg}$ and reviewed in accordance with Principles of Laboratory Animal Care ("Guiding Principles in the Care and Use of Animals" of the American Physiology Society, NIH Publication no. 86-23, revised in 1996) and approved by the Local Ethics Committee at International Centre of Introduction of New Biomedical Technology and Kuban State Medical University, Krasnodar, Russia. The rabbits were kept in a daylight environment and fed commercial laboratory rabbit food pellet, in specially designed housed (animal room) at a mean temperature $20^{\circ} \mathrm{C}$, humidity $40 \%-70 \%$, lighting 12 hours per day for at least 1 week before the experiments.

\subsection{Experimental Protocol Design}

CHF was reproduced by left descending coronary artery stenosis (banding (ligation) up to one third of the original size under sterile conditions [13]) 3-month duration (average ratio of heart to the body mass increased from the $2.22 \pm 0.24$ to $4.05 \pm 0.24(\mathrm{p}>0.001)$ and did not changed in the sham operation group 2.32 \pm 0.19 , NS). Average survival of animals in the interval $2-7$ days was about $78 \%$ (54 from 69 animals in the experiments) in the operation group and $100 \%$ in the sham operated group. After 8 weeks all experimental animals were randomized into three group: control II $(\mathrm{n}=10)$ were treated with either vehicle (normal saline), main group I in which animals received NAD-containing positive inotropic drug Adenocin ${ }^{\circledR}(20 \mathrm{mg} / \mathrm{kg}$ solved in $1 \mathrm{ml}$ of water for injection intravenously, once daily) $(\mathrm{n}=12)$ for 14 days and main II group in which animals received traditional therapy of CHF, containing ACE inhibitors, enalapril (Sigma Aldrich Inc., St. Louis, MO) intramuscularly ( $0.25 \mathrm{mg} / \mathrm{kg}$ body weight/day), furosemide $1.0 \mathrm{mg} / \mathrm{kg}$ intravenously (bolus), and pimobendan (Sigma Aldrich Inc., St. Louis, MO) $0.1 \mathrm{mg} / \mathrm{kg}$ i.v. once daily during 14 days, $\mathrm{n}=11$ ).

\subsection{Registration of Cardiac Hypertrophy, Congestive Heart Failure}

Cardiac hemodynamics and SIRS were determined as described below [7] [11] [12] [13]. The ventricles trimmed of atria and visible blood vessels. The left ventricular weight (LVW) and the ratio of LVW to body weight (LVW/BW) were obtained. The heart weight index was calculated by dividing the heart weight by the body weight in each group and as a cardiac wet-to-dry weight ratio. Wet-todry weight ratios were determined by drying tissue at $70^{\circ} \mathrm{C}$. The brain natriuretic peptide (BNP) was measurement using MyBioSource ELISA assay.

\subsection{Registration of SIRS Development}

The average severity of clinically symptoms of endotoxemia measured by the lethargy score: temperature and behavioral disturbances (the blinded to treatment status, as follows: $0=$ normal activity; $1=$ quiet, spontaneous activity; $2=$ no spontaneous movement, but responsive to touch; 3 = responds only to noxious stimuli; $4=$ unresponsive to noxious stimuli) were $2.5 \pm 0.2$ in control and $2.8 \pm$ 0.3 in main group with CHF before treatment. In control I (sham operated 
group) its equal $0.13 \pm 0.03$

\subsection{Level of Endotoxemia}

Plasma and myocardium content of TNF- $\alpha$ and NF-kB in nuclear fraction of myocardium from left ventricle were determined by ELISA technique using standard kits (RayBiotech, Inc., USA).

Frozen sections of hearts were mixed with $1.5 \mathrm{ml}$ of physiological solution contained $0.5 \% \mathrm{NaN}_{3}$ and homogenized. Supernatants containing cytosolic protein were used to detect the intracardiac cytokines with commercially available enzyme-linked immunosorbent assay (ELISA) kits (TNF- $\alpha$ and IL-6; IL-1 $\beta$ : BioSource International Co., Camarillo, California).

\subsection{Level of Tissue Dysoxia}

The content of NAD and $\mathrm{NADH}$, ratio of lactate/pyruvate in the myocardium homogenate were measurement as described below [4] [7] [11].

\subsection{Level of the Activity of Intrinsic Defense Systems}

The disturbances in the intrinsic defense system activities were measurement by the level of catepsin D activity with and without $0.1 \%$ triton X-100 (as a marker of lysosomal integrity of the myocardium [14] [15]), production of superoxide anion and hydrogen peroxide in mitochondrial fraction of LV myocardium as a markers of deterioration in antioxidant defense system were described below [4] [7] [11].

\subsection{Statistical Analysis}

The statistical significance assessed as the mean \pm standard deviation (SD). Comparison of two means was performed using the Student $t$ test for normally distributed variables and $\mathrm{p}<0.05$ considered significant. Chi-square testing was used to analyze categorical data. All statistical calculations were performed using the Statistical Sciences (SPSS, version 23).

\section{Results}

\subsection{Congestive Heart Failure Symptoms and Heart Function Recovery}

Survival rates up to 3 month after the 14 days Adenocin ${ }^{\circledR}$ treatment animals with SIRS and CHF syndromes exerted beneficial effects on survival, increased by $100 \%$, in group with traditional treatment the final survival rates were $88 \%$, and in control group, $80 \%$. The cardiac hypertrophic index (CHI) in animals with CHF significantly increased above the control, and averaged $2.81 \pm 0.18$, after treatment with pimobendan in combination with benazepril and furosemide was slightly decreased by $11 \%$ and riches control level in group treated with Adeno$\operatorname{cin}^{\circledR}$. Water concentration in LV of myocardium was also increase and exceeded the control level by $6 \%$ (averaged $776 \pm 23 \mathrm{mg} / \mathrm{g}$ in control animals and $814 \pm 25$ 
$\mathrm{mg} / \mathrm{g}$ in CHF group). After treatment with combined therapy containing enalapril, furosemide and pimobendan and monotherapy with Adenocin ${ }^{\circledR}$ water content decreased to $773 \pm 16 \mathrm{mg} / \mathrm{g}(\mathrm{p}<0.05)$. Moreover, the recovery rates for $+\mathrm{dp} / \mathrm{dt}_{\max },-\mathrm{dp} / \mathrm{dt}_{\max }$ and left ventricle end diastolic pressure (LV EDP) were markedly higher in Adenocin ${ }^{\circledR}$-treated group (Table 1).

The prolonged stenosis of coronary artery characterized by simultaneously developing of two syndromes: CHF, as was diagnosed by developing of cardiac hypertrophy, myocardial edema and increasing of level of BNP (Table 1) and SIRS, as diagnosed by increased the markers and symptoms of endotoxemia, tissue dysoxia and decreasing reserve ability of intrinsic defense systems such as antioxidant and lysosomal (Table 2).

\subsection{Severity of SIRS and Efficacy of Therapy for Its Correction}

Inflammatory processes underlie many diseases and syndromes associated with injury of the heart muscle, and acutely, subacutely, and chronically cause structural, functional, and molecular deficits and defects. Many sterile stimuli that can induce inflammation-specifically dead cells and a variety of irritant particles, including crystals, minerals, and protein aggregates. Although this subset of stimuli is structurally very diverse and might appear to be unrelated, there is accumulating evidence that the innate immune system may recognize them in similar ways and stimulate the sterile inflammatory response via common pathways.

Table 1. Cardiac remodeling and congestive symptoms formation in rabbits with ischemic heart damage. Efficacy of pharmacological algorithms of therapy.

\begin{tabular}{|c|c|c|c|c|}
\hline \multirow[b]{2}{*}{ Parameters } & \multirow{2}{*}{$\begin{array}{c}\text { Control I } \\
\text { (practically healthy } \\
\text { animals), } \mathrm{n}=7\end{array}$} & \multicolumn{3}{|c|}{ Chronic ischemic heart damage } \\
\hline & & $\begin{array}{c}\text { Control II } \\
0.9 \% \mathrm{NaCl}, \mathrm{n}=7\end{array}$ & $\begin{array}{c}\text { Main } \mathrm{I} \\
+ \text { traditional treatment, } \mathrm{n}=10\end{array}$ & $\begin{array}{c}\text { Main, II } \\
+ \text { Adenocin }^{\circledR}, \mathrm{N}=11\end{array}$ \\
\hline Body weight, kg & $3.24 \pm 0.14$ & $2.81 \pm 0.14$ & $2.90 \pm 0.21$ & $3.02 \pm 0.18^{\#}$ \\
\hline Heart weight, $g$ & $4.38 \pm 0.22$ & $7.89 \pm 0.28^{* *}$ & $6.28 \pm 0.24^{* * \#}$ & $4.56 \pm 0.21^{\# \#++}$ \\
\hline Left ventricle weight, $g$ & $3.14 \pm 0.12$ & $4.64 \pm 0.18^{* *}$ & $4.35 \pm 0.10^{* \#}$ & $3.17 \pm 0.11^{\# \#++}$ \\
\hline $\begin{array}{c}\text { Cardiac hypertrophic index }{ }^{1} \text { Heart:body } \\
\text { ratio } \times 10^{-3}\end{array}$ & $1.96 \pm 0.21$ & $2.81 \pm 0.18^{* *}$ & $2.51 \pm 0.14^{* \#}$ & $2.17 \pm 0.13^{\# \#+}$ \\
\hline LV:heart ratio & $0.49 \pm 0.04$ & $0.59 \pm 0.04^{*}$ & $0.60 \pm 0.08$ & $0.48 \pm 0.04^{\#}$ \\
\hline Heart dry weight, $g$ & $1.18 \pm 0.04$ & $1.23 \pm 0.08$ & $1.17 \pm 0.07$ & $1.14 \pm 0.05^{\#}$ \\
\hline Cardiac wet-to-dry weight ratio & $5.41 \pm 0.16$ & $6.41 \pm 0.15^{*}$ & $6.22 \pm 0.14^{*}$ & $5.75 \pm 0.20^{\#}$ \\
\hline Relative lung weight, g/kg body & $2.31 \pm 0.12$ & $2.31 \pm 0.12$ & $2.31 \pm 0.12$ & $2.31 \pm 0.12$ \\
\hline $\mathrm{dP} / \mathrm{dt} \max , \mathrm{mmHg} / \mathrm{s}$ & $2456 \pm 345$ & $2456 \pm 345$ & $2456 \pm 345$ & $2456 \pm 345$ \\
\hline $\mathrm{dP} / \mathrm{dt} \min , \mathrm{mmHg} / \mathrm{s}$ & $3100 \pm 410$ & $3100 \pm 410$ & $3100 \pm 410$ & $3100 \pm 410$ \\
\hline $\mathrm{EDP}, \mathrm{mmHg}$ & $5.4 \pm 0.9$ & $15.7 \pm 1.9^{* * *}$ & $14.4 \pm 1.3^{* * *}$ & $5.4 \pm 0.8^{\# \# \#+++}$ \\
\hline $\mathrm{BNP}, \mathrm{pmol} / \mathrm{ml}$ & $4.5 \pm 2.1$ & $18 \pm 3^{* * *}$ & $12.4 \pm 2.4^{* * * \#}$ & $6.1 \pm 2.4^{\# \# \#++}$ \\
\hline
\end{tabular}

Note: 1 - Cardiac hypertrophic index was calculated as a ratio $=$ Heart wet weight $(\mathrm{mg})$ : body weight $(\mathrm{mg}) \times 10^{-3}$; each value remains mean \pm standard deviation, symbols—-significance of difference between the group, ${ }^{*}$ - with control, \#- with $\mathrm{CHF},+-$ with traditional therapy groups; one symbol- $\mathrm{p}<0.05$, two- $\mathrm{p}<0.01 ;$ three- $\mathrm{p}<0.001$. 
Table 2. Cardiac remodeling and congestive symptoms formation in rabbits with ischemic heart damage. Efficacy of pharmacological algorithms of therapy.

\begin{tabular}{|c|c|c|c|c|}
\hline \multirow[b]{2}{*}{ Parameters } & \multirow[b]{2}{*}{$\begin{array}{c}\text { Control I } \\
\text { (practically healthy } \\
\text { animals), } \mathrm{n}=7\end{array}$} & \multicolumn{3}{|c|}{ Chronic ischemic heart damage } \\
\hline & & $\begin{array}{l}\text { Control II } \\
0.9 \% \mathrm{NaCl} \\
\mathrm{n}=7\end{array}$ & $\begin{array}{c}\text { Main I } \\
+ \text { traditional treatment, } \\
\mathrm{n}=10\end{array}$ & $\begin{array}{c}\text { Main, II } \\
+ \text { Adenocin }^{\circledR}, \\
\mathrm{n}=11\end{array}$ \\
\hline \multicolumn{5}{|l|}{ Markers of endotoxemia } \\
\hline Optical density of plasma, $\lambda=282 \mathrm{~nm}$ & $0.24 \pm 0.04$ & $0.81 \pm 0.10$ & $0.90 \pm 0.14$ & $0.29 \pm 0.04^{\#}$ \\
\hline Optical density of erythrocytes, $\lambda=258 \mathrm{~nm}$ & $0.58 \pm 0.04$ & $1.29 \pm 0.10^{* *}$ & $0.92 \pm 0.11^{* \#}$ & $0.56 \pm 0.06^{\# \#++}$ \\
\hline VCAM1c & $245 \pm 24$ & $651 \pm 48^{* *}$ & $435 \pm 23^{* \#}$ & $212 \pm 29^{\# \#}$ \\
\hline TNF- $\alpha$, pg/ml plasma & $2.96 \pm 0.21$ & $12.8 \pm 0.8^{* * *}$ & $10.5 \pm 1.1^{\star \#}$ & $2.2 \pm 0.3^{\# \# \#+++}$ \\
\hline TNF- $\alpha, \mathrm{pg} / \mathrm{mg}$ LV & $2.2 \pm 0.2$ & $23.4 \pm 1.3^{* * *}$ & $20.9 \pm 1.1^{* * *}$ & $2.4 \pm 0.4^{\# \# \#+++}$ \\
\hline NF-kB(p65) activity, o.u. at $450 \mathrm{~nm}$ & $0.12 \pm 0.04$ & $0.30 \pm 0.06$ & $0.28 \pm 0.18$ & $0.14 \pm 0.04^{\# \#++}$ \\
\hline \multicolumn{5}{|l|}{ Markers of tissue dysoxia } \\
\hline $\mathrm{NAD}, \mathrm{nMol} / \mathrm{mg}$ protein & $6.8 \pm 0.6$ & $5.1 \pm 0.6$ & $5.3 \pm 0.4$ & $6.4 \pm 0.5^{\# \# \#++}$ \\
\hline $\mathrm{NADH}, \mathrm{nMol} / \mathrm{mg}$ protein & $6.3 \pm 1.0$ & $7.3 \pm 0.8$ & $7.0 \pm 0.4$ & $6.9 \pm 0.5^{\# \# \#++}$ \\
\hline $\mathrm{NAD} / \mathrm{NADH}$ ratio & $1.08 \pm 0.11$ & $0.70 \pm 0.06$ & $0.76 \pm 0.06$ & $0.93 \pm 0.05^{\# \# \#++}$ \\
\hline Lactate/pyruvate & $2.83 \pm 0.19$ & $8.7 \pm 0.6^{*}$ & $7.8 \pm 0.8^{*}$ & $3.2 \pm 0.6^{\#+++}$ \\
\hline \multicolumn{5}{|l|}{ Markers of tissue intrinsic defense systems reserve } \\
\hline \multicolumn{5}{|l|}{ Antioxidant } \\
\hline Velocity of $\mathrm{O}_{2}^{-}$generation, $\mu \mathrm{Mol} / \mathrm{mg}$ protein $\cdot \mathrm{min}$ & $39 \pm 11$ & $98 \pm 18^{* *}$ & $116 \pm 13^{* \#}$ & $44 \pm 9^{\# \#}$ \\
\hline Hydrogen peroxide, $\mathrm{pmol} / \mathrm{min} \cdot \mathrm{mg}$ & $89 \pm 11$ & $198 \pm 28^{* *}$ & $121 \pm 23^{* \#}$ & $79 \pm 9^{\# \#}$ \\
\hline \multicolumn{5}{|l|}{ Lysosomal } \\
\hline Free Catepsin D activity, $\mu \mathrm{mol}$ thyrosine/mg protein min & $5.5 \pm 0.7$ & $11.8 \pm 1.3^{* * *}$ & $10.4 \pm 1.4^{* * * \#}$ & $6.9 \pm 0.3^{\# \# \#++}$ \\
\hline Total Catepsin D activity, $\mu$ mol thyrosine/mg protein min & $4.5 \pm 0.7$ & $5.9 \pm 1.4^{* * *}$ & $5.4 \pm 1.1^{* * * \#}$ & $5.1 \pm 0.6^{\# \# \#++}$ \\
\hline Lysosomal integrity & $0.82 \pm 0.06$ & $0.50 \pm 0.04^{* * *}$ & $0.52 \pm 0.05^{* * *}$ & $0.74 \pm 0.06^{\# \# \#++}$ \\
\hline
\end{tabular}

Note: each value remains mean \pm standard deviation, symbols—significance of difference between the group, ${ }^{*}$-with control, \#-with CHF, +-with traditional therapy groups; one symbol $-\mathrm{p}<0.05$, two $-\mathrm{p}<0.01$; three $-\mathrm{p}<0.001$.

\subsection{Intensity of Endotoxemia under CHF and Improvement after Treatment}

The SIRS caused by chronic ischemic heart damage 3 month duration characterized by small leucocytosis $\geq 12 \times 10^{9}$ cells/L, stable temperature $37.2^{\circ} \mathrm{C} \pm 2.2^{\circ} \mathrm{C}$, tachycardia $278 \pm 12$ beats $/ \mathrm{min}$. Blood medium-mass molecules (MMM) concentration was revealed reflecting the condition severity, pattern, and manifestation of endogenous intoxication as a key part of SIRS under CHF (Table 2). Changes in spectrograms of plasma and erythrocytes together with the more than 2-fold increase of VCAM-1c confirmed the persistent release of ischemicinduced structural deterioration molecules from the myocardium and their absorption on the glycocalyx or in erythrocytes. This accompanied by elevated level of proinflammatory cytokine, TNF- $\alpha$ in 10 -fold in plasma and in 5.8-fold in 
LV of myocardium in comparison to practically healthy rabbits (Table 2). NF-kB (p65) activity in LV also increases in 2.5 fold in nuclear fraction of LV myocardium. Combined treatment with inhibitor of ACE, pimobendan and diuretics decreased the optical density of erythrocytes and has not changed the content of MMM in plasma, while the content of VCAM1c decreased by $33 \%$ (but it exceeds by $78 \%$ the normal level). This combined therapy has not shown the beneficial inhibitory effects on the TNF $\alpha$ production due to inhibition of activation of NF- $\kappa$ B in myocardium, but decrease the level of TNF $\alpha$ in plasma in 1.7-fold. Treatment with Adenocin ${ }^{\circledR}$ normalized the spectrograms of plasma and erythrocytes, content of VCAMc and decrease the level of TNF $\alpha$ in myocardium and plasma (in 2.9 and 7-fold respectively). Decreasing TNF $\alpha$ in myocardium couples with the normalization of activity of NF-kB in myocardium (decreasing in more than 2 times in comparison with CHF group, $\mathrm{p}<0.01)$.

\subsection{Intensity of Tissue Dysoxia and Efficacy of Treatment}

Under prolonged ischemic heart damage the decreasing the redox-potential $\mathrm{NAD} / \mathrm{NADH}$ by $30 \%$ as a marker of the mitochondrial complex 1 functioning disturbances is occurred which leads to an increasing of generation of superoxide anion. The ratio of lactate/pyruvate increases about 3-fold that strongly confirm that metabolism shift to an anaerobic processes and energy supply deterioration. The decreasing of redox-potential at this stage of CHF has not coupled with reduced of total pool of pyridine nucleotide (including $\mathrm{NADP}(\mathrm{H})$ pool our unpublished dates). The strong negative correlation between increasing level of TNF- $\alpha$ production and NF-kB (p65) activity and redox-potential NAD/NADH $(\mathrm{r}=-0.73, \mathrm{p}<0.001$ and $\mathrm{r}=-0.67, \mathrm{p}<0.01$ respectively $)$ was established. Therapy with of Adenocin ${ }^{\circledR}$ intravenously once daily, unlike traditional treatment, was capable to restore the normal level of $\mathrm{NAD}^{+} / \mathrm{NADH}$ ratio and to decrease the activation of NF-kB and content of TNF-alpha in myocardium and blood and as a result blocking the myocardial hypertrophy progression.

\subsection{Intensity of Tissue Intrinsic Defense Systems Reserve Ability}

Superoxide anion production in the ischemic injuring myocardium significantly increases $(p<0.001)$. Combined treatment with pimobendan has not prevented the increase in superoxide anion production in the myocardium after ischemia (NS). Adenocin reduced superoxide anion production in CHF and SIRS induced by chronic ischemic coronary arteries $(\mathrm{p}<0.001)$. At the same time, influence of the traditional therapy results to the decrease of the hydrogen peroxide production in CHF ischemic genesis myocardium from $198 \pm 28 \mathrm{nmol} / \mathrm{min} / \mathrm{mg}$ to 126 $\pm 23 \mathrm{nmol} / \mathrm{min} / \mathrm{mg}$ ( $\mathrm{p}<0.01 ; 89 \pm 11 \mathrm{nmol} / \mathrm{min} / \mathrm{mg}$ in practically healthy animals myocardium). Hyperproduction of hydrogen peroxide in ischemic genesis CHF myocardium fully diminished under course treatment with Adenocin ${ }^{\circledR}$ (Table 2).

The free and total catepsin D activities increased in hypertrophied myocar- 
dium by $115 \%(\mathrm{p}<0.001)$ and $31 \%(\mathrm{p}<0.01)$, respectively. As a result, the ratio of total activity/free activity of catepsin D decreased by $39 \%$ in CHF myocardium. Following treatment with combined therapy with pimobendan the free activity of catepsin D has not been decrease in comparison with CHF group while the total activity of enzyme significantly has not been changed from normal level. While treatment with Adenocin pronounced decrease, the free catepsin $\mathrm{D}$ activity and ratio of total activity/free activity of this lysosomal enzyme, which indicated that such treatment restores the integrity of lysosomal membrane.

\section{Discussion}

Despite advances in the treatment of cardiac arrest, the development of organ dysfunction following return of spontaneous circulation causes considerable morbidity and mortality. Our article is devoted to the definitions of "stress", "systemic inflammatory response syndrome" and to their equivalence. A new definition of "SIRS-stress reaction" was proposed to clearly depict the essence of the clinical and pathological processes in cardiological patients with "sterile" inflammatory conditions [1] [2] [5]. Statistically significant negative correlation was shown between the level of redox-potential and the activity of NF-kB in LV myocardium, along with negative correlation between the level of NAD/NADH and TNF- $\alpha$ in LV myocardium and plasma in peripheral blood. The purpose of the present study was to test the hypothesis that inotropic drug with pronounced cardioprotective properties, Adenocin ${ }^{\circledR}$, would significantly reduce the severity of endogenous intoxication, ischemic/hypoxic severity of myocardium and activation of inflammatory and oxidative stressing signaling pathways. These multipoint actions of Adenocin ${ }^{\circledR}$ improved cardiac dysfunction under $\mathrm{CHF}$ and SIRS [15]. The traditional treatment containing pimobendan, an inhibitor of phosphodiesterase III with additional calcium-sensitizing properties, ACE inhibitor enalapril and furosemide, prolonged survival, attenuated inflammatory lesions, and decreased the production of cytokines, but in much less extent that monotherapy with Adenocin ${ }^{\circledR}$. In comparison with other phosphodiesterase III inhibitor, pimobendan strongly inhibited the production of NO in cultured macrophages stimulated by lipopolysaccharide. Pimobendan and iACE are independently effective in acute and chronic heart failure throughout improving cardiac hemodynamics and survival in experimental CHF caused by myxomatous mitral valve disease [16]. It was shown early that oral enalapril inhibited hydrogen peroxide released by unstimulated PMN, but did not affect stimulated $\mathrm{H}_{2} \mathrm{O}_{2}$ release, superoxide anion production, adhesion or aggregation of PMN. Enalaprilat in vitro stimulated $\mathrm{PMN}$ to release $\mathrm{H}_{2} \mathrm{O}_{2}$ and superoxide anions. Furthermore, in the in vitro conditions both enalaprilat and enalapril inhibited hydrogen peroxide released by stimulated cells and despite certain modifications of neutrophil function in vitro, oral administration of enalapril seems to exert a limited biological effect on circulating neutrophils [17]. Unlike Adenocin ${ }^{\circledR}$ tradi- 
tional combined therapy does not have beneficial action on the redox-potential and pool of oxidized NAD (Table 2). Directly decreasing of superoxide anion hyperproduction under treatment with Adenocin ${ }^{\circledR}$ due to the restoration of redox-potential, NAD/NADH, leads to the deactivation of NF- $\kappa \mathrm{B}$ and decreasing proinflammatory cytokine production (TNF- $\alpha$ ), as well as restoration of lysosomal integrity. Cardio-inflammation is currently a hot topic, primarily due to its association with CHF which has become a highly significant therapeutic target. Obtained results confirmed with dates showed that tissue capacity to produce TNF $\alpha$ appears to be directly correlated with intracellular levels of NAD in myocardium, suggesting a NAD-dependent regulation and functional link between metabolism and inflammation [18] [19] and blocking cardiac maladaptive responses [18]. Inotropic component of Adenocin, beta-acetyldigoxin, strengthens the anti-inflammatory effects of NAD throughout inhibition ROR $\gamma t$ transcriptional activity and modulation activation of Ras-Raf-MAPK-inositol triphosphate receptor activity which is associated with activity of nuclear transcription factor NF-kB [20]-[26]. Obtained results demonstrated that cardioprotective drug Adenocin ${ }^{\circledR}$ confirmed in clinical trial cardiotonic action during various etiology CHF in patients, prevents the progression of cardiac hypertrophy, myocardial edema and intensity of all signs and symptoms of SIRS. Adenocin ${ }^{\circledR}$ has the ability to control the regulatory pathways of TNF- $\alpha$ synthesis, and causes a cessation of the hypoxic/ischemic and free radical-induced damage in myocardium. This indicates that it may have therapeutic potential in the treatment of CHF [27]. Because, compared with traditional therapy, Adenocin ${ }^{\circledR}$ is more potent in its reduction of LVH; the mechanism of its antihypertrophic action, in addition to standard therapy, could involve inhibition of the proinflammatory activities of cytokines, as one of the main targets of CHF progression and SIRS formation.

\section{Acknowledgements}

We express appreciation for E. Tsivtsivadze, PhD, Director of "Biotechpharm GE”, Ltd Georgia, for the provision of preparation Adenocin ${ }^{\circledR}$ for investigation.

\section{Conflict of Interest}

The authors declare that they have no conflict of interests regarding the publication of this paper.

\section{References}

[1] Rock, K.L., Latz, E., Ontiveros, F. and Kono, H. (2010) The Sterile Inflammatory Response. Annual Review of Immunology, 28, 321-342. https://doi.org/10.1146/annurev-immunol-030409-101311

[2] Liu, T.F., Brown, C.M., El Gazzar, M., et al. (2012) Fueling the Flame: Bioenergy Couples Metabolism and Inflammation. Journal of Leukocyte Biology, 92, 499-507. https://doi.org/10.1189/jlb.0212078

[3] Jankowaska, E.A., Ponikowski, P., Piepoli, M.F., et al. (2006) Autonomic Imbalance 
and Immune Activation in Chronic Heart Failure-Pathophysiologic Links. Cardiovascular Research, 70, 434-445. https://doi.org/10.1016/j.cardiores.2006.01.013

[4] Bokeria, L.A., Malikov, V.E., Arzumanyan, M.A., et al. (2008) Rational Pharmacological Correction of the Systemic Inflammatory Response Syndrome in Patients with Decrease Contractile Function. Hematologia, 2, 45-53.

[5] Linde, A., Mosier, D., Blecha, F. and Melgarejo, T. (2007) Innate Immunity and Inflammation-New Fronties in Comparative Cardiovascular Pathology. Cardiovascular Research, 73, 26-36. https://doi.org/10.1016/j.cardiores.2006.08.009

[6] Chen, H., Wang, J., Wang, J.-A. and Shi, G.-P. (2011) Role of Lysosomal Cathepsins in Post-Myocardial Infarction Remodeling. North American Journal of Medical Sciences, 4, 173-177. https://doi.org/10.7156/v4i4p173

[7] Sukoyan, G. and Antelava, N.A. (2009) Rational Drug Correction of Systemic Inflammatory Response Syndrome in Severe Experimental Heart Failure. Bulletin of Experimental Biology and Medicine, 147, 391-394.

https://doi.org/10.1007/s10517-009-0528-9

[8] Chini, C.C.S., Espindolla-Netto, J.M., Mondal, G., et al. (2016) SIRT1-Activating Compounds (STAC) Negatively Regulate Pancreatic Cancer Cell Growth and Viability through a SIRT1 Lysosomal-Dependent Pathway. Clinical Cancer Research, 22, 2496-2507. https://doi.org/10.1158/1078-0432.CCR-15-1760

[9] Stoppelkamp, S., Veseli, K., Stang, K., et al. (2015) Identification of Predictive Early Biomarkers for Sterile-SIRS after Cardiovascular Surgery. PLoS One, 10, e0135527. https://doi.org/10.1371/journal.pone.0135527

[10] Fosko, M.J., Ceretti, V. and Agranatti, D. (2010) Systemic Inflammatory Response Syndrome Predicts Mortality in Acute Coronary Syndrome without Congestive Heart Failure. The Western Journal of Emergency Medicine, XI, 373-378.

[11] Ionov, D., Galenko-Iaroshevsky, P., Sukoian, G. and Dolidze, N. (2012) Novel Targets for Therapeutic Action of Heart Failure in Experiments. $6^{\text {th }}$ European Congress of Pharmacology, Granada, 17-20 July 2012, 83-85.

[12] Sukoyan, G.V. and Gongadze, N.V. (2010) Comparative Therapeutic Efficacy of Adenocin and Non-Glycoside Cardiotonic Drugs in Chronic Heart Failure at Rest and Under Conditions of Heart Overload. Bulletin of Experimental Biology and Medicine, 149, 714-717. https://doi.org/10.1007/s10517-010-1033-x

[13] Sukoyan, G.V. and Gongadze, N.V. (2010) Mechanism of Cardioprotective Effect of Adenocine and Non-Glycoside Cardiotonic Drugs during Experimental Chronic Cardiac Insufficiency. Bulletin of Experimental Biology and Medicine, 151, 542-545.

[14] Megreladze, I.I., Gongadze, N.V., Kezeli, T.D., et al. (2013) Targets of Therapy of Patients with Congestive Heart Failure Caused by Ischemic Heart Disease and Diabetes. Clinical Therapeutic, 35, e46-e48. https://doi.org/10.1016/j.clinthera.2013.07.127

[15] Barret, A.J. and Heath, M.F. (1977) Lysosomal Enzymes. In: Dingle, T.J., Ed., Lysosome: Laboratory Handbook, North Holland, Amsterdam, 124-126.

[16] Nerurkar, M.A., Satav, J.G. and Katyare, S.A. (1988) Insulon Dependent Changes in Lysosomal Cathepsin D Activity in Rat, Liver, Kidney, Brain and Heart. Diabetologua, 31, 119-122. https://doi.org/10.1007/BF00395559

[17] Preyat, N., Rossi, M., Kers, J., et al. (2016) Intracellular Nicotinamide Adenine Dinucleotide Promotes TNF-Induced Necroptosis in a Sirtuin-Dependent Manner. Cell Death and Differentiation, 23, 29-40. https://doi.org/10.1038/cdd.2015.60

[18] Matsumori, A., Ono, K., Nishio, R., et al. (1997) Modulation of Cytokine Produc- 
tion and Protection against Lethal Endotoxemia by the Cardiac glycoside Ouabain. Circulation, 96, 1501-1506. https://doi.org/10.1161/01.CIR.96.5.1501

[19] Häggström, J., Lord, P.F., Höglund, K., et al. (2013) Short-Term Hemodynamic and Neuroendocrine Effects of Pimobendan and Benazepril in Dogs with Myxomatous Mitral Valve Disease and Congestive Heart Failure. Journal of Veterinary Internal Medicine, 27, 1452-1462. https://doi.org/10.1111/jvim.12217

[20] Wysocki, H., Siminiak, T., Zozulinska, D. and Wierusz-Wysoska, B. (1995) Evaluation of the Effect of Oral Enaprilat on Neutrophils Functions: Comparison with the in Vitro Effect of Enalapril and Enalaprilat. Polish Journal of Pharmacology, 47, 53-58.

[21] Pillai, V.B., Sundaresan, N.R., Kim, G., et al. (2010) Exogenous NAD Blocks Cardiac Hypertrophic Response via Activation of the SIRT3-LKB1-AMP-Activated Kinase Pathway. The Journal of Biological Chemistry, 285, 3133-3144.

https://doi.org/10.1074/jbc.M109.077271

[22] Vachharajiani, V.T., Liu, T., Wang, X., et al. (2016) Sirtuins Link Inflammation and Metabolism. Journal of Immunology Research, 2016, Article ID: 8167273. https://doi.org/10.1155/2016/8167273

[23] Fujita-Sato, S., Ito, S., Isobe, T., et al. (2011) Structural Basis of Digoxin That Antagonizes ROR Gamma t Receptor Activity and Suppresses Th17 Cell Differentiation and Interleukin (IL)-17 Production. The Journal of Biological Chemistry, 286, 31409-31417. https://doi.org/10.1074/jbc.M111.254003

[24] Adams, K.F., Ghali, J.K., Patterson, J.H., et al. (2014) A Perspective on Re-Evaluating Digoxin's Role in the Current Management of Patients with Chronic Systolic Heart Failure: Targeting Serum Concentration to Reduce Hospitalization and Improve Safety Profile. European Journal of Heart Failure, 16, 483-493. https://doi.org/10.1002/ejhf.64

[25] Lee, J., Baek, S., Lee, J., et al. (2015) Digoxin Ameliorates Autoimmune Arthritis via Suppression of Th17 Differentiation. International Immunopharmacology, 26, 103-111. https://doi.org/10.1016/j.intimp.2015.03.017

[26] Zeng, M., Yan, H., Zhao, H.-J., et al. (2012) Suppression of NF-kB Reduces Myocardial No-Reflow. PLoS ONE, 7, e47306.

https://doi.org/10.1371/journal.pone.0047306

[27] Galenko-Yaroshevsky, P.A., Sukoyan, G.V., Ionov, D.I., et al. (2017) Possibility of TNF/NF-kB Signaling Pathway Activation in Myocardium and Reverse Cardiac Hemodynamics in Chronic Ischemic Heart Diseases. Journal of Clinical and Experimental Pathology, 7, 3. 